\title{
Change in olfactory function after septoplasty. A systematic review and meta-analysis*
}

\author{
Alejandro Grabosky', Paula Mackers², Cristóbal Langdonn, ${ }^{3,4}$ Isam Alobid ${ }^{3,4}$ \\ Rhinology 59: 2, 144 - 150, 2021 \\ https://doi.org/10.4193/Rhin20.252 \\ Medical Graduate, University of Barcelona, Barcelona, Spain \\ 2 Department of Otorhinolaryngology, Hospital del Mar, Barcelona, Spain \\ *Received for publication: \\ ${ }^{3}$ Rhinology and Skull base Unit, Department of Otorhinolaryngology, Hospital Clínic, Universitat de Barcelona. IDIBAPS Barcelona, May 22, 2020 \\ Spain \\ Accepted: October 22, 2020 \\ ${ }^{4}$ Centre for Biomedical Research on Respiratory Diseases (CIBERES). Barcelona, Spain
}

\begin{abstract}
Background: Septoplasty is one of the most frequently performed surgeries. However, there remains a question as to the effect of such intervention on the sense of smell. This study aims to examine the available evidence regarding the effect of septoplasty on the sense of smell.
\end{abstract}

Methods: A database search was performed using PubMed, ScienceDirect, Google Scholar and The Cochrane Library databases from January 1990 to February 2020. Search terms included smell, olfaction, odor, septum, septoplasty, and septorhinoplasty. A meta-analysis was performed with 12 studies that provided sufficient data on change in olfaction.

Results: 14 studies met the inclusion criteria, and 2 additional studies were included manually; comprising a total of 996 patients and 25 controls. Significant improvement in olfactory test scores was observed in all tests. Pre- and postoperative differences in means were 0.63 for BSIT, 0.80 for CCCRC test, 1.16 for odor threshold, 1.43 for odor discrimination, and 1.18 for odor identification.

Conclusions: Septoplasty seems to improve olfactory function. However, the outcome of this intervention is discrete and not equal for all patients, so further randomized trials are needed to confirm current findings.

Key words: smell, olfaction, nasal septum, septoplasty, Sniffin' Sticks, CCCRC, BSIT

\section{Introduction}

The sense of smell is responsible for perceiving and processing aromatic compounds. Inhaled particles pass through the nasal cavity to the neurons of the olfactory epithelium, which then synapse in the olfactory bulb. The signals are delivered to multiple locations in the brain where they are interpreted as recognizable odors ${ }^{(1,2)}$. Therefore, it is assumable to think that anatomical alterations of structures such as the nasal septum or the nasal turbinates can alter this airflow and compromise olfaction ${ }^{(3-6)}$. Nasal obstruction is one of the most common symptoms in sinonasal disease and can stem from various conditions such as rhinitis, turbinate hypertrophy, adenoid hypertrophy, or nasal masses ${ }^{(3)}$. However, nasal septum deviation is one of the most common, present in three-quarters of patients who consult for symptoms of nasal obstruction ${ }^{(7)}$ mostly in secondary and tertiary centers. Likewise, olfactory dysfunction (OD) due to decreased nasal airflow is reported to be a common complaint among patients with nasal septum deviation ${ }^{(4,8)}$.

OD might have a negative impact on many aspects of daily life, including food appreciation, personal hygiene, social communication, and detection of environmental risks such as spoiled food or smoke ${ }^{(5)}$. Therefore, OD due to septal deviation can substantially affect the quality of life of patients. Septoplasty is the standard treatment for nasal septum deviation because it generally results in improved nasal airflow and resolution of nasal obstruction symptoms; however, it is not without side effects ${ }^{(9)}$. To date, there are multiple studies evaluating the effects of septal surgery on olfactory function and nasal symptoms with conflicting results ${ }^{(2,4-6,10-21)}$.

There are many tests designed for assessing olfaction objec- 
tively. Each has a different methodology and scoring system with which the subjects are classified as anosmic, hyposmic, or normosmic ${ }^{(22-24)}$.

The purpose of this systematic review and meta-analysis is to examine the available evidence and assess the change in sense of smell of patients with septal deviation who undergo septoplasty.

\section{Materials and Methods}

The review protocol was based on the Preferred Reporting Items for Systematic Reviews and Meta-analyses guidelines.

\section{Search strategy}

A database search was performed using PubMed, Science Direct, Google Scholar, and the Cochrane Library encompassing records from January 1990 to February 2020. The search terms and details are shown in (Supplements, Table 1). Bibliographies of included studies were cross-referenced to manually identify additional articles.

\section{Selection of studies}

Inclusion criteria were research and review articles relating to: 1) any septoplasty technique with or without turbinate resection for nasal obstruction due to septal deviation; 2) assessment of olfaction before and after surgery without restrictions on followup time. Exclusion criteria were: 1) surgery for reasons other than nasal obstruction due to deviated septum (i.e. cosmetic, sinusitis, rhinitis, polyps, concha bullosa...); 2) lateralized assessment of olfaction (each nostril scored separately); 3) no available translation into English or Spanish language. Communications, case reports and case series, book chapters, encyclopedia entries, conference abstracts, letters and other correspondence, discussions, and scientific posters were excluded.

\section{Outcomes}

The main outcome was the mean change in olfactory test score after septoplasty. Other outcomes were change in percentage of patients classified as anosmic, hyposmic, and normosmic before and after surgery.

\section{Assessment of risk of systematic bias}

The methodological quality of the included studies was examined using the NIH Guidance for Assessing the Quality of Before-After (Pre-Post) Studies with No Control Group(25), which rates 12 domains as "yes", "no", or "not applicable". The overall quality was valued as good, fair, or poor.

\section{Data extraction}

The following information was extracted from each included study and sorted in a Microsoft ${ }^{\circledR}$ Excel v16.0 spreadsheet: author name, publication year, sample size, surgical technique/s performed, used test or questionnaire, mean follow-up time/s, preand post-op values, and reported results of the intervention. Characteristics of included studies are presented in Table 1. For studies with more than one branch, only the branches that met the inclusion criteria were included.

\section{Summary of data}

A qualitative synthesis was performed for the results from olfactory tests.

\section{Statistical analysis}

At this point, the authors of the included studies were contacted to obtain the correlation coefficient of the pre- and postoperative scores. For the rest of studies, the correlation coefficient used was the average of the reported coefficients (0.6543). To ensure that the results were robust enough, sensitivity analyses were conducted setting the correlation coefficient at 0.8 and 0.5 . STATA $^{\oplus} 16.0$ (StataCorp., College Station, TX, USA) software was used for the meta-analysis. The difference in means in olfactory function was calculated for 2 studies reporting BSIT scores ${ }^{(12,18)}$, 4 reporting CCCRC scores $(6,13,15,20), 4$ reporting all three subsets of the Sniffin' Sticks test ${ }^{(4,5,14,21)}$ and 2 reporting SST OI scores ${ }^{(10,11)}$. For clearer interpretation, the meta-analysis was conducted on a raw difference in means instead of a standardized one. The studies by Kokubo et al. ${ }^{(21)}$, Miyake et al. ${ }^{(16)}$, and Tutar et al. ${ }^{(2)}$ were excluded because no numerical values were reported for the olfactory test results. The study by Randhawa et al. ${ }^{(17)}$ was excluded because standard deviations were not reported. For studies with multiple follow up-times, the results from the longest follow-up time were used. For studies with more than one study branch, each branch was considered as a separate study. The test for heterogeneity was conducted using the 12 statistic describing the percentage of variation across studies originating from heterogeneity rather than from chance. To calculate the effect sizes, a random effects model was used. However, because each test measures olfaction differently they can't be pooled together, so no overall effect size can be calculated.

Publication bias was evaluated by funnel plot and Egger's regression test. The Duval and Tweedie trim-and-fill method was used to correct the effect size to account for potentially unpublished reports. Results were reported as mean, $95 \% \mathrm{Cl}$, and $\mathrm{P}$ values.

\section{Results}

Six hundred and seventy records were identified, with 81 duplicates removed. 589 abstracts were screened, and 25 full-text articles reviewed, with 14 studies meeting the criteria for inclusion. Two additional articles were found after cross-referencing the bibliography of included studies. Figure 1 shows the flow diagram of the report selection. 
Table 1. Characteristics of included studies.

\begin{tabular}{|c|c|c|c|c|c|c|}
\hline Study & $\mathbf{n}$ & $\begin{array}{l}\text { Type of } \\
\text { surgery }\end{array}$ & $\begin{array}{l}\text { Olfac- } \\
\text { tory test }\end{array}$ & FU & Pre-op & Post-op \\
\hline $\begin{array}{l}\text { Damm et al. }{ }^{(4)} \text {, } \\
2003\end{array}$ & 30 & SP, IT & $\begin{array}{l}\text { SST (OT, } \\
\text { OD, OI) }\end{array}$ & $4 \mathrm{~m}$ & $\begin{array}{l}7 \% \text { were anosmic; } 60 \% \text { hyposmic and } \\
33 \% \text { normosmic }\end{array}$ & $\begin{array}{l}0 \% \text { were anosmic; } 20 \% \text { hyposmic and } \\
80 \% \text { normosmic. Significant improve- } \\
\text { ment of OT, OD, Ol scores, albeit modest } \\
\text { in OT }\end{array}$ \\
\hline $\begin{array}{l}\text { Pade et al. }{ }^{(10)} \\
2008\end{array}$ & 150 & SP & SST OI & $4 \mathrm{~m}$ & Mean identification score of 12.31 (2.29) & $\begin{array}{l}\text { Mean identification score of } 12.81 \text { (2.02). } \\
\text { Improvement in } 13 \% \text {, no change in } 81 \% \text {, } \\
\text { and decreased function in } 7 \%\end{array}$ \\
\hline $\begin{array}{l}\text { Schriever et } \\
\text { al. }^{(11)}, 2013\end{array}$ & 44 & SP, IT & SST OI & $12 \mathrm{~m}$ & Mean identification score of 12.12 (3.7) & $\begin{array}{l}\text { Mean identification score of } 12.6 \text { (2.52). } \\
\text { No significant change in identification } \\
\text { score }\end{array}$ \\
\hline $\begin{array}{l}\text { Dengiz et al. }{ }^{(12)} \text {, } \\
2015\end{array}$ & 53 & SRP & BSIT & $4 w, 12 w$ & Mean preoperative score of 10.15 (1.30) & $\begin{array}{l}\text { Change in mean BSIT score was not } \\
\text { significant at } 4 \mathrm{w} \text {, but became significant } \\
\text { at } 12 \mathrm{w} \text { postoperatively }\end{array}$ \\
\hline $\begin{array}{l}\text { Berkiten et al. }{ }^{(13)} \text {, } \\
2016\end{array}$ & 50 & SP & CCCRC & $6 w$ & Mean score of 3.81 (0.89) & Statistically significant improvement \\
\hline $\begin{array}{l}\text { Dalgic et al. }{ }^{(14)} \\
2016\end{array}$ & $\begin{array}{l}21 \\
18\end{array}$ & $\begin{array}{l}\mathrm{SP}(\mathrm{ts}) \\
\mathrm{SP}(\mathrm{m})\end{array}$ & $\begin{array}{l}\text { SST (OT, } \\
\text { OD, OI) }\end{array}$ & $1 \mathrm{w}, 3 \mathrm{~m}$ & $\begin{array}{l}\text { Mean composite score of hyposmia ( } 29.6 \\
\text { group A (ts); } 29.5 \text { group B (m)) }\end{array}$ & $\begin{array}{l}\text { OT, OD and OI scores increased signifi- } \\
\text { cantly at } 3 \mathrm{~m}\end{array}$ \\
\hline $\begin{array}{l}\text { Kilicaslan et } \\
\text { al. }^{(15)}, 2016\end{array}$ & 37 & SP & CCCRC & $\begin{array}{l}1 \mathrm{w}, 6 \mathrm{w} \\
6 \mathrm{~m}, 1 \mathrm{y}\end{array}$ & $\begin{array}{l}2.7 \% \text { had moderate hyposmia, } 10.8 \% \\
\text { mild hyposmia, and } 86.5 \% \text { normosmia }\end{array}$ & $\begin{array}{l}\text { Total olfaction worsened at } 1 \mathrm{w} \text {, was the } \\
\text { same as pre-op after } 6 \mathrm{w} \text {, and improved } \\
\text { after } 6 \mathrm{~m} \text { and } 1 \mathrm{y} \text {. By } 6 \mathrm{~m} \text { all patients had } \\
\text { become normosmic. }\end{array}$ \\
\hline $\begin{array}{l}\text { Miyake et al. }{ }^{(16)}, \\
2016\end{array}$ & 110 & SP, SRP & CCCRC & $\begin{array}{l}1 \mathrm{~m}, \geq 3 \\
\mathrm{~m}\end{array}$ & $\begin{array}{l}\text { Normosmia in } 68.1 \% \text { of patients, mild } \\
\text { hyposmia in } 6.4 \% \text {, mod-erate hyposmia } \\
\text { in } 8.2 \% \text {, sever hyposmia in } 10 \% \text {, anosmia } \\
\text { in } 7.3 \%\end{array}$ & $\begin{array}{l}39.3 \% \text { of patients improved, } 46.4 \% \\
\text { remained the same, and } 14.2 \% \text { worse- } \\
\text { ned } 3 \text { or more months after surgery }\end{array}$ \\
\hline $\begin{array}{l}\text { Randhawa et } \\
\text { al. }{ }^{(17)}, 2016\end{array}$ & 43 & SRP & SST (OD) & $12 w$ & NR & $\begin{array}{l}\text { Significant change in SST score. } 58 \% \\
\text { improved, 35\% remained the same, } 7 \% \\
\text { worsened }\end{array}$ \\
\hline $\begin{array}{l}\text { Haytoglu et } \\
\text { al. }^{(18)}, 2017\end{array}$ & $\begin{array}{l}41(\mathrm{~s}) \\
75(\mathrm{~ns})\end{array}$ & SP & BSIT & $1 \mathrm{~m}, 3 \mathrm{~m}$ & $\begin{array}{l}\text { Mean preoperative scores of } 8.8(1.2) \text { in } \\
\text { smokers (s) and } 8.6(1.2) \text { in non-smokers } \\
\text { (ns). No differences between smoking } \\
\text { habit }\end{array}$ & $\begin{array}{l}\text { BSIT scores worsened at } 1 \mathrm{~m} \text {, but } \\
\text { improved above baseline at } 3 \mathrm{~m} \text { in both } \\
\text { smokers and non-smokers }\end{array}$ \\
\hline $\begin{array}{l}\text { Turk et al. }{ }^{(19)} \\
2017\end{array}$ & 30 & SP & $\begin{array}{l}\text { SST (OT, } \\
\text { OD, OI) }\end{array}$ & $6 w$ & $\begin{array}{l}33.3 \% \text { of patients were normosmic, } \\
60.0 \% \text { hyposmic, and } 6.7 \% \text { anosmic }\end{array}$ & $\begin{array}{l}\text { Significant improvement in SST scores. } \\
63.3 \% \text { of patients were normosmic, } \\
36.7 \% \text { hyposmic, and none anosmic } 6 \mathrm{w} \\
\text { after surgery. }\end{array}$ \\
\hline $\begin{array}{l}\text { Aydogdu et al. }{ }^{(6)} \text {, } \\
2019\end{array}$ & $\begin{array}{l}25 \\
14\end{array}$ & $\begin{array}{l}\mathrm{SP}(\mathrm{c}) \\
\mathrm{SP}(\mathrm{e})\end{array}$ & CCCRC & $8 w$ & $\begin{array}{l}\text { Mean preoperative scores of } 3.01(0.57) \\
\text { and } 2.92(0.49) \text { for conventional and ex- } \\
\text { tracorporeal septoplasties, respectively }\end{array}$ & $\begin{array}{l}\text { Significant improvement. No differences } \\
\text { between surgical techniques }\end{array}$ \\
\hline $\begin{array}{l}\text { Elbistanli et } \\
\text { al. }^{(20)}, 2019\end{array}$ & 20 & SP & CCCRC & $1 \mathrm{~m}, 4 \mathrm{~m}$ & The mean score was $6.05(0.9)$ & $\begin{array}{l}\text { Worsening of olfaction at } 1 \mathrm{~m} \text { and reco- } \\
\text { vering of baseline olfaction at } 4 \mathrm{~m} \text {. }\end{array}$ \\
\hline $\begin{array}{l}\text { Kokubo et al. }{ }^{(21)} \text {, } \\
2019\end{array}$ & 34 & SRP & UPSIT & $4 w 12 w$ & $\begin{array}{l}79.4 \% \text { of patients had normosmia, } 14.7 \% \\
\text { mild hyposmia, and } 5.9 \% \text { moderate } \\
\text { hyposmia }\end{array}$ & $\begin{array}{l}76.5 \% \text { of patients had normosmia, } 20.6 \% \\
\text { mild hyposmia, and } 2.9 \% \text { moderate hy- } \\
\text { posmia. No change in USPIT score after } 4 \\
\text { w nor } 12 \text { w postoperatively }\end{array}$ \\
\hline $\begin{array}{l}\text { Valsamidis et } \\
\text { al. }^{(5)}, 2019\end{array}$ & $\begin{array}{l}60 / 25 \\
\text { con- } \\
\text { trols }\end{array}$ & SP & $\begin{array}{l}\text { SST (OT, } \\
\text { OD, OI) }\end{array}$ & $6 \mathrm{~m}$ & $\begin{array}{l}31.66 \% \text { were normosmic and } 68.33 \% \\
\text { had olfactory deficits. Significantly lower } \\
\text { scores than controls in all SST sub-tests }\end{array}$ & $\begin{array}{l}\text { Significantly improved olfactory func- } \\
\text { tion, but still worse than controls }\end{array}$ \\
\hline $\begin{array}{l}\text { Tutar et al. }{ }^{(2)}, \\
2020\end{array}$ & 141 & SP & $\begin{array}{l}\text { SST (OT, } \\
\text { OD, OI) }\end{array}$ & $\begin{array}{l}1 \mathrm{w}, 6 \mathrm{w} \\
6 \mathrm{~m}\end{array}$ & $\begin{array}{l}1.4 \% \text { were anosmic, } 13.5 \% \text { hyposmic, } \\
\text { and } 85.1 \% \text { normosmic }\end{array}$ & $\begin{array}{l}0.7 \% \text { of patients had anosmia at } 1 \mathrm{w} \\
\text { and } 0 \% \text { at } 6 \mathrm{w} \text { and } 6 \mathrm{~m} .17 .7 \% \text { were hy- } \\
\text { posmic at } 1 \mathrm{w}, 6.4 \% \text { at } 6 \mathrm{w} \text {, and } 2.8 \% \text { at } 6 \\
\mathrm{~m} .81 .6 \% \text { had normosmia at } 1 \mathrm{w}, 93.6 \% \\
\text { at } 6 \mathrm{w} \text {, and } 97.2 \% \text { at } 6 \mathrm{~m} \text {. }\end{array}$ \\
\hline
\end{tabular}

n: number of patients, FU: follow-up, m: months, w: weeks, y: years. SP: Septoplasty, SRP: Septorhinoplasty, IT: surgery of the Inferior Turbinate. SST: Sniffin' Sticks Test, OT: Olfactory Threshold, OI: Olfactory Identification, Olfactory Discrimination, CCCRC: Connecticut Chemosensory Clinical Research Center test, BSIT: Brief Smell Identification Test, UPSIT: University of Pennsylvania Smell Identification Test. ts: transseptal sutures, m: merocele packing, c: classical septoplasty, e: extracorporeal septoplasty. Unless specified, values reported as mean (SD). NR: Not Reported. 


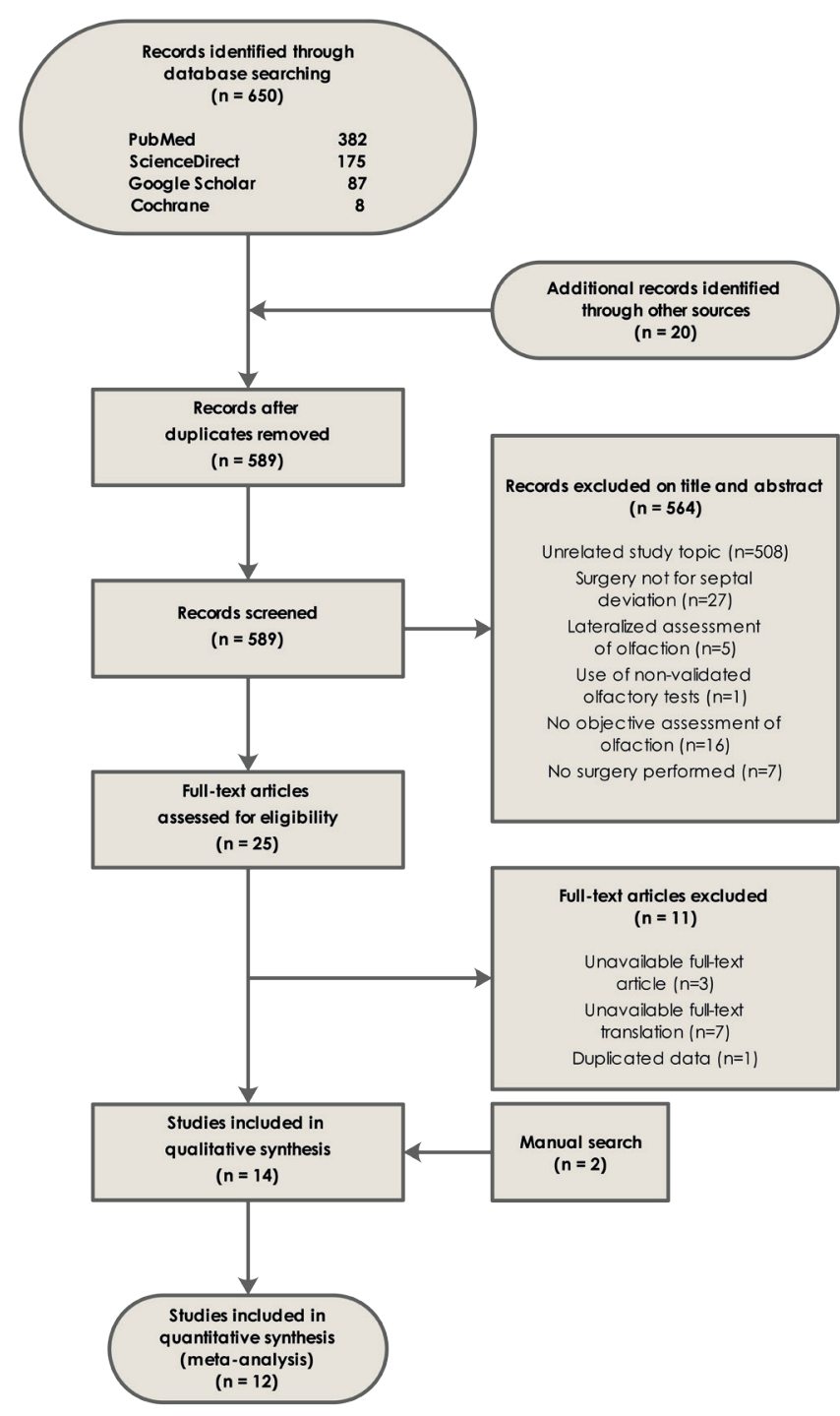

Figure 1. PRISMA Flow Diagram. QoL: quality of life.

\section{Study characteristics}

Of the 16 included studies, all were prospective observational studies except $2(13 \%)$ randomized controlled trials(2,14), 8 studies used some form of the Sniffin' Sticks Test $(2,4,5,10,11,14,17,19) 5$ studies used the Connecticut Chemosensory Clinical Research Center (CCCRC) test $(6,13,15,20)$ and 2 used Brief Smell Identification Test (BSIT) to score olfaction $(12,18)$. One study used the University of Pennsylvania Smell Identification Test (UPSIT)(21). The total sample size was 996 patients and 25 controls. Individual studies' size ranged from 30 to 150 patients, follow-up durations ranged from 1 week to 1 year, and patient ages ranged from 10 to 85 years.

\section{Risk of systematic bias}

Of the included 16 studies, methodologically 7 were considered to be $\operatorname{good}^{(2,12,14,15,18,20,21)}, 7$ were considered fair $(4-6,13,16,17,19)$, and 2 were considered poor $\left({ }^{10,11)}\right.$ (Table 2).

\section{Olfactory tests}

Seven studies included data on the distribution of patients as normosmic, hyposmic or anosmic. In 4 of those studies the majority of patients were normosmic ${ }^{(2,15,16,21)}$, whereas in 3 studies the majority of patients had OD before surgery ${ }^{(4,5,19)}$. The study by Valsamidis et al. ${ }^{(5)}$ included healthy subjects and found that patients with septal deviation had worse olfaction than controls. Of the 16 studies assessing olfactory function, 11 found a significant improvement in olfactory test scores after septoplasty $(2,4-6,12-15,17-19)$, whereas 5 found that septoplasty did not improve smell perception ${ }^{(10,11,16,20,21)}$. Furthermore, Pade et al. ${ }^{(10)}$, Miyake et al. ${ }^{(16)}$, and Randhawa et al. ${ }^{(17)}$ found worsening of olfactory function after septoplasty in $7 \%, 14.2 \%$, and $7 \%$ of their patients, respectively.

\section{BSIT}

The total sample size of the included studies using the BSIT test was 169 patients. The calculated difference in means was 0.63 ( $95 \% \mathrm{Cl}, 0.43$ to 0.84 ) (Figure $2 \mathrm{~A}$ ), which represents a $7.01 \% \mathrm{im}$ provement over the average preoperative BSIT score. The heterogeneity was moderate $(I 2=45.64 \%)$. There was no significant publication bias (Egger's regression intercept $P=0.2835$ ) and no trim-and-fill imputations were needed.

\section{CCCRC}

Studies using the CCCRC test had a total population of $166 \mathrm{pa}-$ tients. The pooled difference in means was $0.80(95 \% \mathrm{Cl}, 0.26$ to 1.33) (Figure 2B), which represents a $17.42 \%$ improvement over the average preoperative CCCRC score. However, the heterogeneity was very high ( $12=96.54 \%)$. The Egger's regression test did not detect evidence of publication bias $(P=0.9013)$ and no trim-and-fill imputations were needed.

\section{Sniffin' Sticks test}

Only two of the included studies using the Sniffin' Sticks Test reported the combined score,5,33 so each of the test's three subtests was analyzed separately. The number of patients administered the complete Sniffin' Sticks Test was 159, with 194 additional patients on the identification subtest. The pooled difference in means was $1.16(95 \% \mathrm{Cl}, 0.55$ to 1.76$)$ for odor threshold (Figure $2 \mathrm{C}$ ), 1.43 ( $95 \% \mathrm{Cl}, 0.86$ to 2.00 ) for odor discrimination (Figure 2D), and $1.18(95 \% \mathrm{Cl}, 0.74$ to 1.63$)$ for odor identification (Figure 2E). These differences represent a 20.30\%, 13.62\%, and $10.23 \%$ improvement over the average preoperative scores. Heterogeneity for the Sniffin' Sticks Test was significant, being highest in the identification subtest $(12=81.78 \%)$ and lowest in the discrimination subtest $(12=76.65 \%)$. Heterogeneity for the threshold test was $I 2=81.29 \%$. There was no publication bias, as indicated by Egger's regression intercept P-values of $0.3592,0.7087$, and 0.6079 for the threshold, discrimination and 
Table 2. Risk of bias within studies.

\begin{tabular}{|c|c|c|c|c|c|c|c|c|c|c|c|c|c|}
\hline Item Stud & 1 & 2 & 3 & 4 & 5 & 6 & 7 & 8 & 9 & 10 & 11 & 12 & Total \\
\hline Damm et al. ${ }^{(4)}, 2003$ & Yes & Yes & Yes & NA & NR & No & Yes & No & Yes & Yes & No & NA & Fair \\
\hline Pade et al. ${ }^{(10)}, 2008$ & Yes & Yes & Yes & NA & NR & No & Yes & No & No & Yes & No & NA & Poor \\
\hline Schriever et al. ${ }^{(11)}, 2013$ & Yes & Yes & Yes & NA & NR & No & Yes & No & No & Yes & No & NA & Poor \\
\hline Dengiz et al. ${ }^{(12)}, 2015$ & Yes & Yes & Yes & NA & NR & No & Yes & No & Yes & Yes & Yes & NA & Good \\
\hline Berkiten et al. ${ }^{(13)}, 2016$ & Yes & Yes & Yes & NA & NR & No & Yes & No & Yes & Yes & No & NA & Fair \\
\hline Dalgic et al. ${ }^{(14)}, 2016$ & Yes & Yes & Yes & NA & NR & No & Yes & No & Yes & Yes & Yes & NA & Good \\
\hline Kilicaslan et al. ${ }^{(15)}, 2016$ & Yes & Yes & Yes & NA & NR & No & Yes & No & Yes & Yes & Yes & NA & Good \\
\hline Miyake et al. ${ }^{(16)}, 2016$ & Yes & Yes & Yes & NA & NR & No & Yes & No & No & Yes & Yes & NA & Fair \\
\hline Randhawa et al. ${ }^{(17)}, 2016$ & Yes & Yes & Yes & NA & NR & No & Yes & No & Yes & Yes & No & NA & Fair \\
\hline Haytoglu et al. ${ }^{(18)}, 2017$ & Yes & Yes & Yes & NA & NR & No & Yes & No & Yes & Yes & Yes & NA & Good \\
\hline Turk et al. ${ }^{(19)}, 2017$ & Yes & Yes & Yes & NA & NR & No & Yes & No & Yes & Yes & No & NA & Fair \\
\hline Aydogdu et al. ${ }^{(6)}, 2019$ & Yes & Yes & Yes & NA & NR & No & Yes & No & Yes & Yes & No & NA & Fair \\
\hline Elbistanli et al. ${ }^{(20)}, 2019$ & Yes & Yes & Yes & NA & NR & No & Yes & No & Yes & Yes & Yes & NA & Good \\
\hline Kokubo et al. ${ }^{(21)}, 2019$ & Yes & Yes & Yes & NA & NR & No & Yes & No & Yes & Yes & Yes & NA & Good \\
\hline Valsamidis et al. ${ }^{(5)}, 2019$ & Yes & Yes & Yes & NA & NR & No & Yes & No & Yes & Yes & No & NA & Fair \\
\hline Tutar et al. ${ }^{(2)}, 2020$ & Yes & Yes & Yes & NA & NR & No & Yes & No & Yes & Yes & Yes & NA & Good \\
\hline
\end{tabular}

NA: Not Applicable; NR: Not Reported

identification tests respectively. In no case were trim-and-fill imputations needed.

\section{Sensitivity analysis}

Because assumptions were made regarding the correlation coefficients of the pre- and postoperative scores, sensitivity analyses were performed setting the correlation coefficient at 0.8 and 0.5 . The results obtained did not differ from the final results.

\section{Discussion}

Patients with septal deviation have reduced olfaction compared to the general population(5), which may negatively affect their daily lives. OD is probably due to a restriction on the airflow by the deviated nasal septum and seems reasonable to think that correcting this anatomical defect would improve olfaction. However, the published data hasn't been able to conclusively provide evidence to support this claim and studies diverge on their findings.

Although surgery can be suggested as the treatment for some cases of OD, nasal surgery may harm olfactory epithelium and worsen olfactory function. This assertion is supported by studies showing that early preoperative $(\leq 6 \mathrm{w})$ scores had not improved or were even worse than before the septoplasty, but improved at later follow-up times ${ }^{(12,14,15,18,20)}$. Nasal surgical procedures may distort intranasal anatomy or cause direct trauma to the olfactory epithelium. Likewise, they could have indirect effects arising from pharmacological agents, mucosal edema or blood clots, causing potential damage to the olfactory nerve and com- promise olfaction ${ }^{(13,20)}$. Since it can take several months for full recovery of the nasal structures after surgery ${ }^{(26)}$, the evidence from studies with short follow-up times should be interpreted carefully.

Furthermore, a finding of some studies was that patients with more severe nasal obstruction had worse baseline olfaction and obtained more benefit from septoplasty compared to those patients with milder obstruction ${ }^{(3,5)}$. While this is not surprising, the high heterogeneity of assessing nasal obstruction makes it difficult to reliably determine the level of symptom severity that is indicative of significant benefit from septoplasty ${ }^{(26)}$.

For those reasons, there is a need to identify prognostic factors for septoplasty and further research is required to find objective methods that better assess the outcome of surgical interventions on the nasal septum. Since it is paramount to any surgical intervention that benefits outweigh its risks, obtaining knowledge of outcome predictors will ensure better patient selection, such that both subjective and objective measures of success can be proven.

Septoplasty seems to improve olfactory function. However, the outcome of this intervention is discrete and not equal for all patients, so more researches are needed.

\section{Limitations}

The study is limited by the heterogeneity across studies, which complicates discerning the factors affecting the outcome of septoplasty. A source for this heterogeneity could be differences in patient characteristics such as age or severity of their 


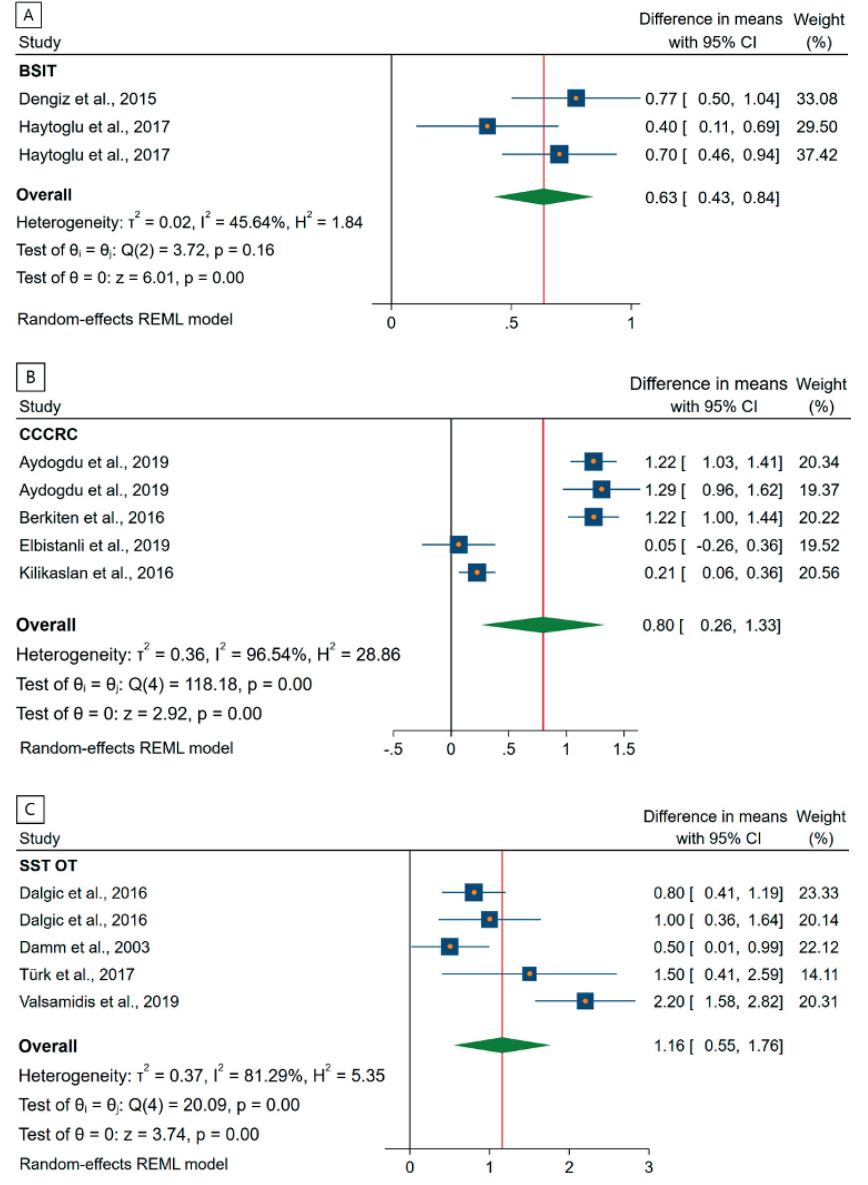

obstruction, as well as presence of concomitant causes of nasal obstruction or other rhinologic conditions. Also, the use of different septoplasty techniques among the included studies and non-standardization of the tools used to assess olfaction could be behind de observed heterogeneity.

\section{Conclusion}

Septal deviation compromises the sense of smell and septoplasty seems effective in resolving nasal obstruction due to septal deviation. This review shows that septoplasty has some effect on improving patient's olfaction, yet further randomized trials are
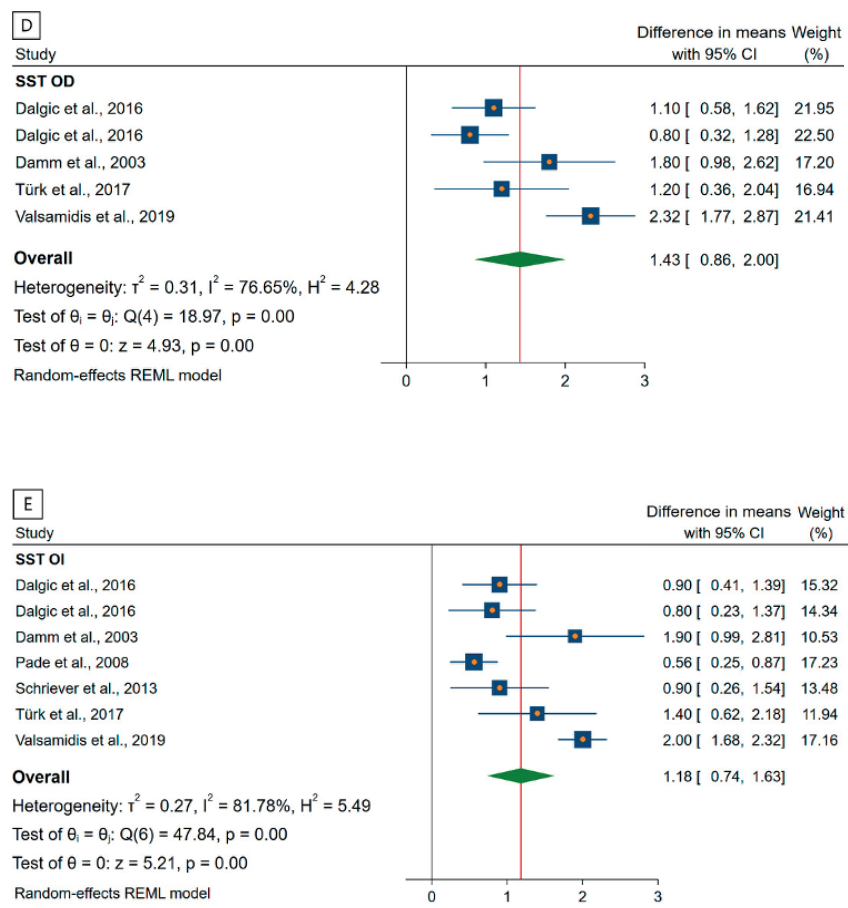

Figure 2. Forest Plots. A: meta-analysis of Brief Smell Identification Test (BSIT) scores; B: meta-analysis of Connecticut Chemosensory Clinical Research Center (CCCRC) scores; C: meta-analysis of Odor Threshold scores; D: meta-analysis of Odor Discrimination scores; E: meta-analysis of Odor Identification scores.

needed to confirm current findings.

\section{Acknowledgements}

None

\section{Authorship contribution}

AG and PM: Literature review and search, prepare the manuscript. CL and IA: Prepare and review the manuscript

\section{Conflict of interest}

None.

\section{References}

1. Altundag A, Salihoglu M, Tekeli H, et al. Lateralized differences in olfactory function and olfactory bulb volume relate to nasal septum deviation. J Craniofac Surg 2014:25(2):359-62.

2. Tutar B, Ekincioglu E, Karaketir S, et al. The impact of platelet-rich fibrin (PRF) on olfactory function and pain after septoplasty operations. Eur Arch Otorhinolaryngol. 2020;277(4):1115-20

3. Gupta N, Singh PP, Bagla RK. Will Septa Correction Surgery for Deviated Nasa Septum Improve the Sense of Smell? A Prospective Study. Surg Res Pract.
2015;2015:496542.

4. Damm M, Eckel HE, Jungeholsing $M$, et al. Olfactory changes at threshold and suprathreshold levels following septoplasty with partial inferior turbinectomy. Ann Otol Rhinol Laryngol. 2003;112(1):91-7.

5. Valsamidis K, Printza A, Titelis K, et al Olfaction and quality of life in patients with nasal septal deviation treated with septoplasty. Am J Otolaryngol - Head Neck Med Surg. 2019;40(5):747-54.

6. Aydogdu I, Atar Y, Aydog Z, et al. Comparison of olfactory function and quality of life with different surgical techniques for nasal septum deviation. J Craniofac Surg.
2019;30(2):433-6.

7. Clark DW, Del Signore AG, Raithatha R, et al. Nasal airway obstruction: Prevalence and anatomic contributors. Ear, Nose Throat J [Internet]. 2018;97(6):173-6.

8. Moore M, Eccles R. Objective evidence for the efficacy of surgical management of the deviated septum as a treatment for chronic nasal obstruction: A systematic review. Clin Otolaryngol. 2011;36(2):106-13.

9. Kimmelman CP. The risk to olfaction from nasal surgery. Laryngoscope. 1994;104(8 Pt 1):981-8.

10. Pade J, Hummel T. Olfactory function following nasal surgery. Laryngoscope. 
2008;118(7):1260-4.

11. Schriever VA, Gupta N, Pade J, et al. Olfactory function following nasal surgery: a 1-year follow-up. Eur Arch Otorhinolaryngol. 2013;270(1):107-11.

12. Dengiz R, Haytoglu S, Gorgulu O, et al Effect of Septorhinoplasty on Olfactory Function: Assessment Using the Brief Smel Identification Test. Turk Otolarengoloji Arsivi/Turkish Arch Otolaryngol. 2015;53(1):4-9.

13. Berkiten G, Kumral TL, Saltürk Z, et al. Effect of deviated nasal septum type on nasal mucociliary clearance, olfactory function, quality of life, and efficiency of nasal surgery. J Craniofac Surg. 2016;27(5):1151-5.

14. Dalgic A, Is A, Dinc ME, et al. The effects of nasal packing and transseptal suturing after septoplasty on olfactory function, patient comfort, and mucociliary clearance. J Craniofac Surg. 2016;27(5):e487-90.

15. Kilicaslan A, Acar GO, Tekin M, et al. Assessment the long-term effects of septoplasty surgery on olfactory function. Acta Otolaryngol. 2016:136(10):1079-84.

16. Miyake MM, Miyamura BV, Grunewald RE, et al. Avaliação do olfato de pacientes submetidos à septoplastia e rinoseptoplastia no Hospital Central Santa Casa de São Paulo. 2016;117-22.

17. Randhawa PS, Watson N, Lechner M, et al, The outcome of septorhinoplasty surgery on olfactory function. Clin Otolaryngol. 2016:41(1):15-20

18. Haytoğlu S, Dengiz R, Muluk NB, et al. Effects of septoplasty on olfactory function evaluated by the Brief Smell Identification Test: A study of 116 patients. Ear Nose Throat J. 2017;96(10-11):433-8.

19. Türk $B, A$ Akpinar $M$, Altundağ $A$, et al. The Effect of External Approach Septoplasty on Olfactory Function. J Craniofac Surg. 2017;28(7):1675-8.

20. Elbistanli MS, Koçak HE, Çelik M, et al. Significance of medial osteotomy on the olfactory function in patients who underwent septorhinoplasty. J Craniofac Surg. 2019;30(2):E106-9.

21. Kokubo LCP, Carvalho TBO, Fornazieri MA, et al. Effects of septorhinoplasty on smell perception. Eur Arch Oto-Rhino-Laryngology. 2019;276(4):1247-50.

22. Menon C, Westervelt HJ, Jahn DR, et al. Normative Performance on the Brief Smell Identification Test (BSIT) in a Multi-Ethnic Bilingual Cohort: A Project FRONTIER Study. Clin Neuropsychol. 2013;27(6):946-61.

23. Veyseller B, Ozucer B, Karaaltin AB, et al Connecticut (CCCRC) Olfactory Test: Normative Values in 426 Healthy Volunteers. Indian J Otolaryngol Head Neck Surg. 2014;66(1):31-4.

24. Rumeau C, Nguyen DT, Jankowski R. How to assess olfactory perfor- mance with the Sniffin' Sticks test ${ }^{\oplus}$. Eur Ann Otorhinolaryngol Head Neck Dis. 2016;133(3):203-6.

25. National Heart, Lung, and Blood institute. NIH Study Quality Assessment Tools: Quality Assessment Tool for Before-After (Pre-Post) Studies With No Control Group. Bethesda: $\mathrm{NIH}$. Available from: https://www.nhlbi.nih. gov/health-topics/study-quality-assessment-tools.

26. Tsang CLN, Nguyen T, Sivesind T, et al. Longterm patient-related outcome measures of septoplasty: a systematic review. Eur Arch Oto-Rhino-Laryngology. 2018;275(5):103948.

Isam Alobid, MD, PhD

Rhinology and Skull base Unit

Hospital Clínic i Universitari

Villarroel 170

08036 Barcelona

Spain

Tel: +34 932279872

Fax: +34 932279813

E-mail: isamalobid@gmail.com 


\section{SUPPLEMENTARY DATA}

Table S1. Detailed search strategy.

\begin{tabular}{|c|c|c|c|}
\hline No. & Databases & Search Terms & Result Total $=650$ \\
\hline 1 & PubMed & $\begin{array}{l}\text { (("Nasal Septum"[Mesh]) AND "Smell"[Mesh]) OR ((smell OR olfaction OR } \\
\text { odor) AND (septoplasty OR septum OR septal)) }\end{array}$ & 381 \\
\hline 2 & ScienceDirect & ((smell OR olfaction OR odor) AND septoplasty) & 174 \\
\hline 3 & Google Scholar & $\begin{array}{l}\text { Where my words occur: in the title of the article: } \\
\text { 1. With all of the words: septoplasty } \\
\text { With at least one of the words: smell olfaction olfactory odor } \\
\text { 2. With all of the words: septal } \\
\text { With at least one of the words: smell olfaction olfactory odor } \\
\text { 3. With all of the words: septorhinoplasty } \\
\text { With at least one of the words: smell olfaction olfactory odor } \\
\text { 4. With all of the words: septum } \\
\text { With at least one of the words: smell olfaction olfactory odor }\end{array}$ & $15+43+6+23=87$ \\
\hline 4 & Cochrane & $\begin{array}{l}\text { In all text and ENT Cochrane group: } \\
\text { (smell OR olfaction) AND septoplasty }\end{array}$ & 8 \\
\hline
\end{tabular}

